\title{
BMJ Open Malnutrition and contributing factors among newborns delivered at the University of Gondar Hospital, Northwest Ethiopia: a cross-sectional study
}

\author{
Almaz Tefera Gonete (D) ,' Tewodros Getaneh Alemu, ${ }^{1}$ \\ Eskedar Getie Mekonnen (D) , ${ }^{2}$ Wubet Worku Takele (D) ${ }^{3}$
}

To cite: Gonete AT, Alemu TG, Mekonnen EG, et al. Malnutrition and contributing factors among newborns delivered at the University of Gondar Hospital, Northwest Ethiopia: a crosssectional study. BMJ Open 2021;11:e053577. doi:10.1136/ bmjopen-2021-053577

- Prepublication history for this paper is available online. To view these files, please visit the journal online (http://dx.doi. org/10.1136/bmjopen-2021053577).

Received 22 May 2021 Accepted 18 October 2021

Check for updates

(C) Author(s) (or their employer(s)) 2021. Re-use permitted under CC BY-NC. No commercial re-use. See rights and permissions. Published by BMJ.

${ }^{1}$ Department of Pediatrics and Child Health Nursing, University of Gondar, Gondar, Ethiopia

${ }^{2}$ Reproductive Health, University of Gondar College of Medicine and Health Sciences, Gondar, Amhara Regional State, Ethiopia ${ }^{3}$ Department of Community Health Nursing, University of Gondar, Gondar, Ethiopia

Correspondence to Wubet Worku Takele; wubetakele380@gmail.com

\section{ABSTRACT}

Objectives To estimate the prevalence of various indicators of malnutrition (stunting, wasting, low birth weight, concurrent stunting and wasting, overweight/obesity and double burden malnutrition) among newborns and to investigate factors associated with these nutritional disorders.

Methods A hospital-based cross-sectional study was conducted from 10 March through to May 2020. A total of 419 newborns were recruited into the study to estimate the prevalence of low birth weight and stunting. After excluding 28 newborns whose length was less than $45 \mathrm{~cm}$, 394 newborn-mother dyads were approached to estimate wasting and overweight/obesity. A systematic random sampling technique was used to select participants. All independent variables were entered into the multivariable logistic regression model and variables that had significant associations were identified based on a $p$ value.

Results A very small proportion of the newborns $2.5 \%$ $(0.9 \%$ to $4.1 \%)$ were concurrently wasted and stunted. The prevalence rates of low birth weight and wasting were $20.8 \%(16.8 \%$ to $24.6 \%)$ and $10.9 \%(7.82 \%$ to $14.01 \%)$, respectively. The magnitude of overweight/obesity was $12.7 \%(9.3 \%$ to $15.9 \%)$ where $2.8 \%$ (1.1\% to $4.4 \%)$ of newborns have the double burden of malnutrition. Having a father with a primary level of education 2.82 (1.19 to 6.65) and being stunted at birth 3.17 (1.6 to 6.0) were variables that were associated with increased odds of low birth weight. The odds of being overweight/obese are significantly higher among newborns born to mothers who are urban dwellers 0.35 (0.12 to 0.99).

Conclusions The study underscores that malnutrition is a pressing public health concern that demands due emphasis. Fathers' educational status (low level) and being stunted are associated with a high burden of low birth weight. Mothers' residency (being urban) is associated with an elevated risk of overweight/obesity among newborns. Thus, improving the health literacy of fathers and preventing stunting at birth are recommended to mitigate low birth weight.

\section{INTRODUCTION}

Stunting, wasting and low birth weight (LBW) are the predominant forms of undernutrition that usually occurred in children of developing countries, where the socioeconomic
Strengths and limitations of this study

- The prevalence of various forms of malnutrition (both overnutrition and undernutrition) is estimated which yields a piece of comprehensive evidence.

- This is the only study in Ethiopia that reported the concurrent and double burden of malnutrition among newborns.

- The anthropometric measurements reported are adjusted for the gestational age.

- Paternal-related variables such as height that would have an impact on the nutritional status of newborns were not included because of the inaccessibility of fathers during delivery.

- Maternal mental health status that is presumed to be a contributing factor for malnutrition has not been considered as a factor and tested for association.

status, literacy level and dietary practices are poor. ${ }^{12}$ Multiple nutritional disorders (concurrent/double burden of malnutrition (DBM) ) would also happen to a child that further increases the likelihood of developing short-term and long-term untoward consequences. $^{2}$ Concurrent wasting and stunting (WaSt) at birth, for instance, is the most common concomitant nutritional disorder, which is characterised by being thin for weight and short for age at a time. Similarly, the occurrence of overweight/obesity with stunting simultaneously is termed as the DBM, which is an emerging nutritional problem. $^{3}{ }^{4}$ Following the swift nutrition transition, DBM is becoming an increasing problem in different countries of the world that largely compromises the growth and development of children. ${ }^{56}$ The emergence of DBM and WaSt has ruined the lives of millions of young children across the globe. ${ }^{2}$

Globally, malnutrition is a threat to the lives of one-third $(33.8 \%)$ of children younger than 5 years, of which Africa contributes the 
biggest share of the burden at $98 \% .^{5}$ About 8 million $(2 \%)$ of children younger than 5 years are suffering from DBM. ${ }^{7}$ Similarly, the overall burden of concurrent WaSt in this segment of the population ranged between $2.35 \%$ and $3 \% .{ }^{8}$ In children younger than 5 years, wasting and stunting have contributed to 64.6 and 54.9 million disability-adjusted life years, respectively, which accounted for $14.8 \%$ and $12.6 \%$ of the total global disability-adjusted life years. ${ }^{68}$ Ethiopia, a country with the highest burden of malnutrition, $44 \%$ and $27 \%$ of children below 5 years and under 6 months of age, respectively, are affected. ${ }^{1011}$ Nearly half of the under-5 mortality in Ethiopia is also imputed by malnutrition. ${ }^{5} 9$ Moreover, $16.5 \%$ of the country's gross domestic product and about US $\$ 157.8$ US $\$ 230.2$ million are lost annually owing to the long-term and short-term effects of malnutrition, respectively. ${ }^{12-15}$

Malnutrition has both short-term and long-term shattering effects that impacted not only the lives of children but also extend to affect the subsequent generations. ${ }^{371617}$ Undernutrition, in particular, in early life results in impairment of cognitive development, irreversible physical and physiological destruction, and puts children at higher risk of morbidity and mortality. ${ }^{18} 19$ It also contributes to incur non-communicable diseases like type 2 diabetes due to the rushed weight gain in the later life. $^{56919-22}$

Childhood malnutrition, particularly among newborns, is usually attributed to poor nutrition in utero and repeated bouts of infection that start from conception. ${ }^{23}$ Multifaceted reproductive and maternal nutritional and medical disorders are likewise the contributing factors of malnutrition among newborns. ${ }^{25}$ The likelihood of developing malnutrition is associated with short maternal stature, poor maternal nutritional status, illness during pregnancy (diabetes mellitus, hypertension, anaemia, and toxoplasmosis rubella, cancroid and herpes simplex virus (TORCH) infection), having no antenatal care (ANC) visit, short pregnancy interval, maternal age (advanced and younger) and not supplemented with iron folate during pregnancy. ${ }^{25-31}$

To curve the observed, Ethiopia has been working to end malnutrition through designing various programmes, including the National Nutrition Program and the Seqota Declaration to achieve the World Health Assembly's target of reducing stunting to $26.8 \%$ by 2025 . Nonetheless, the annual average reduction rate (AARR) of stunting is only $2.8 \%$, which is far off the expected decline rate of $6 \%{ }^{32}$ Similarly, the annual average reduction rate of wasting is $0.1 \%$ that is still remarkably lower than the expected AARR, which is $5 \% .^{13}$

Despite the findings that show the burden and contributing factors of malnutrition among newborns can be used as preliminary evidence for further intervention, the existing pieces of evidence are concentrated only on children aged 6-59 months. The burden of malnutrition among newborns is supposed to be high in Ethiopia associated with high maternal malnutrition in the country though there is no study that reveals the prevalence and contributing factors. The aim of this study was, therefore, to estimate the prevalence of wasting, stunting, concurrent WaSt, LBW, overweight/obesity and DBM, as well as to identify the contributing factors. Understanding the problem at an earlier stage will provide a spotlight for local decision-makers, project planners and policymakers for designing programmes to mitigate the burden through strengthening care during pregnancy, tackle the ill effects at the right time and halt the combined negative effect of various types of malnutrition.

\section{METHODS AND MATERIALS}

\section{Patient and public involvement}

Mothers and their newborns were included in this study by providing their valuable information including measurements. However, they have never participated in conducting the study, designing the protocol and data collection tools, reporting the results and disseminating the study findings.

\section{Study design and period}

A hospital-based cross-sectional study was conducted from 10 March to May 2020. The study was prepared using the Strengthening the Reporting of Observational studies in Epidemiology.

\section{Study period and area}

The study was carried out at the University of Gondar Comprehensive Specialized Referral Hospital situated in the Amhara region, northwest of Ethiopia. The region has been affected by the high prevalence of malnutrition, lesser economic development and poor infrastructure. $^{33} 34$ The hospital is a teaching hospital that tailors health services for about 5 million clients from the central Gondar Zone and other neighbouring zones.

\section{Study participants}

Alive newborns right after birth to 72 hours of age were included. Nevertheless, newborns whose mothers were suffering from critical illnesses like postpartum haemorrhage were excluded. Similarly, newborns suffering from an illness and who were very and extremely preterm were excluded to ascertain LBW and stunting at birth. In addition, newborns whose length was less than $45 \mathrm{~cm}$ were excluded to determine wasting, overweight/obesity, concurrent WaSt and DBM. ${ }^{35}$

\section{Sample size determination}

The required sample size for investigating the prevalence of malnutrition was determined using Epi Info considering the single population proportion formula by taking the following statistical assumptions: proportion $(\mathrm{p})$ : 50\%; CIs: 95\%; margin of error: $5 \%$ and non-response: $10 \%$.

$\mathrm{n}=(\mathrm{Z} \alpha / 2) 2 \quad \mathrm{p} \quad(1-\mathrm{p}) / \mathrm{d}^{2}=(1.96) 2 \quad(0.5) \quad(0.5) /$ (0.05) 2=which was increased to 384 after adding $10 \%$ of non-response. Thus, 422 mother-newborn pairs were invited and approached. 


\section{Sampling procedure and technique}

An estimated 10599 newborns were delivered at the University of Gondar Comprehensive Specialized Referral Hospital delivery ward per annum. For the purpose of the current study, we randomly selected 4 months (1 month from each of the four seasons). This season-based stratification was important because the number of birth varies throughout the four seasons; accordingly, an average of 884 live births was assumed to occur per month. ${ }^{36}$ Systematic random sampling technique was employed and for sampling purposes, the value of ' $\mathrm{K}$ ' (to be used as the length of the interval in systematic random sampling) was estimated using the formula $\mathrm{N} / \mathrm{n}=884 / 422$ and found to be 2 .

\section{Variables of the study}

Outcome variables: stunting, wasting, concurrent WaSt, LBW, overweight/obesity and DBM.

\section{Independent variables}

Sociodemographic variables: age, marital status, residence, religion, maternal occupation, maternal education status and paternal education status.

Maternal-related factors: ANC visit, interbirth interval, maternal height, illness during pregnancy, mid-upper arm circumference (MUAC), gravidity, parity, gestational age, pregnancy intention and history of iron supplementation.

Newborn-related factors: sex, maturity status and birth status (singleton vs multiple).

Environmental factors: indoor fire smoke and season of conception.

\section{Definition of variables \\ Outcome variables}

Stunting: newborns whose length-for-gestational age measurement was $<10$ centile. ${ }^{37}$

LBW: newborns whose weight-for-gestational age was $<10$ centile. ${ }^{37}$

Wasting: newborns whose WHZ (weight-for-height) measurement was $<(-2 \mathrm{SD}) .^{16}$

Concurrent WaSt: newborns who were concomitantly wasted and stunted. ${ }^{4}$

Overweight/obesity: newborns whose WHZ (weightfor-length) measurement was $>\left(+2 \mathrm{SD} .^{16}\right.$

DBM: newborns who had overweight/obesity and stunting simultaneously. ${ }^{16}$

\section{Independent variables}

Maternal nutrition characteristics

Short maternal stature: mothers whose height measurement was $<145 \mathrm{~cm}^{25}$

Maternal undernutrition: mothers whose MUAC value was $<22 \mathrm{~cm}^{38}$

Anaemic woman: a woman whose haemoglobin measure was below $11 \mathrm{~g} / \mathrm{dL}^{39}$

Reproductive/obstetrics and maternal morbidity characteristics

Short interbirth interval: if the interval between the index birth and the older child is $<24$ months. ${ }^{40}$
Primigravida: a women who conceived for the first time. ${ }^{41}$

Multigravida: a woman who got pregnant more than once. $^{41}$

Primiparous: a women who give birth one time. ${ }^{41}$

Multipara: a woman who gave birth more than once. ${ }^{41}$

Unintended pregnancy: if mothers reported the current pregnancy was unwanted or mistimed. ${ }^{42}$

Illness during pregnancy: mothers who had at least one of the following illnesses during pregnancy: diabetes mellitus, hypertension, anaemia, and infections like hepatitis B, HIV and TORCH. ${ }^{27}$

Wealth status: classified as richest, rich, middle, poorer and poorest, for participants who fall in the first, second, third, fourth and fifth ranks, respectively, using an index generated by the principal component analysis (PCA). ${ }^{43}$

Newborn characteristics

Term: newborns delivered between 37 and 42 weeks. ${ }^{44}$

Preterm: newborns delivered before completing 37 weeks. $^{44}$

\section{Data collection tool and procedures}

A face-to-face structured and interviewer-administered questionnaire developed after reviewing different pieces of literature was used. Maternal illness during pregnancy and some newborn characteristics were collected through chart review. Various anthropometric measurements have been measured and collected. The newborns were placed in recumbent supine position and length was measured by two BSc nurses, one who assisted and supported to keep the head stable and the other who took the measurement from the top of the head to the heel of the foot. The procedure was repeated three times using infanto-metre (ITEM CODE: WS025 and SIZE18'X7'); the average length of the measurements was recorded to the nearest of $0.5 \mathrm{~cm}$ to ensure its accuracy. Likewise, the weight of the newborns was measured using a unit scale made by the UNICEF. The measurement was recorded at the nearest $10 \mathrm{~g}$. All anthropometric measurements were taken within 72 hours of birth and analysed using the INTERGROWTH-21st project and the WHO software. ${ }^{37}$

\section{Stunting and wasting}

To measure stunting, the length of newborns with the corresponding gestational age was gathered, and a composite variable (length-for-gestational age) was generated using the INTEGROWTH-21st software. Similarly, wasting was ascertained through collecting the length and weight of a newborn to create a composite variable (length-for-weight) by using the WHO Anthro software.

\section{Concurrent WaSt}

The two outcome variables (stunting and wasting) were summed up to generate a variable, 'concurrent WaSt', after ascertaining the two outcome variables separately using the appropriate and corresponding composite variables. 


\section{Overweight/obesity}

This was collected by measuring the length and weight of the newborns to produce a composite variable (lengthfor-weight) using WHO Anthro.

\section{Double burden of malnutrition}

DBM was generated by combining stunting and overweight/obesity.

\section{Maternal height}

The height of mothers was measured using a wall stadiometer in a standing position. The measurement was recorded to the nearest $0.5 \mathrm{~cm}$.

\section{Maternal MUAC}

Maternal MUAC was measured by using fibre tape from the left upper arm at the midpoint between the tip of the shoulder (the acromion) and the tip of the elbow (the olecranon process). To ensure accuracy, repeated measurements with an increment of $0.1 \mathrm{~cm}$ were taken.

\section{Wealth status}

A questionnaire adapted from the Ethiopian Demographic and Health Survey, 2016 and other literature was used to collect all necessary data that can help to determine the wealth status of the study participants. The tool was comprised of the number and kinds of livestock that participants had, availability of agricultural land, the amount of cereal products they gathered (in tone), the amount of money deposited in the bank and availability of materials in their house. After recoding each of the variable to have a value of ' 0 ' or ' 1 ', the PCA was applied to construct wealth index. ${ }^{43}$ Data were collected by two BSc midwives supervised by one MSc nurse who earned a degree in paediatric nursing.

\section{Data quality control}

We did a pretest at the University of Gondar Comprehensive Specialized Referral Hospital 2 weeks ahead of the actual data collection period by recruiting 21 eligible newborn-mother pairs. The quality of the data was assured through careful planning and using a properly translated questionnaire. The content of the questionnaire and extraction formats were reviewed by a senior paediatrician and paediatric nurse specialist to maintain the validity of the tool. Questions were checked for clarity, completeness, consistency and ambiguity; corrections were made accordingly.

One-day training was delivered to the data collectors and supervisor aiming at briefing the objective of the study, the anthropometric measurements and so forth. Anthropometric measurements were calibrated each day before starting data collection. Repeated anthropometric measurements have been taken and the average was considered. Furthermore, the principal investigator, together with the supervisor, has checked the collected data for its completeness and takes corrective measures on a daily basis.

\section{Data processing and analysis}

The collected data were entered into Epi Info 7 V.7.2.1.0 and exported to SPSS V.20 for coding, cleaning and analyses. Continuous independent variables were categorised. The household wealth status was determined using PCA. In doing this, all categorical and continuous variables were categorised so that the value for every variable gets either ' 0 ' or ' 1 '. During extracting the underlying factors, factors with communality value of $\geq 0.5$ and Eigenvalues of 1 were retained. Next, all eligible factor scores were computed using the regression-based method to generate one variable that stands for wealth status. The final scores were categorised into five quantiles namely: first, second, third, fourth and fifth, and they were, respectively, interpreted as richest, richer, middle, poorer and poorest, respectively.

The INTERGROWTH-21st software was used to analyse LBW and stunting. The newborn's length in centimetre and the corresponding gestational age were entered to produce 'stunting'; whereas weight in kilogram and the respective gestational age were entered so as to generate 'LBW'. Similarly, using the WHO Anthro software, the newborn's wasting status and overweight/obesity were analysed. The newborn's length, identification number, age (0 months), weight in kilogram and sex were entered to determine wasting and overweight/obesity. After generating the variables, the flags (Height-for-Age (HAZ) $<(-5 \mathrm{SD})$ and $>(+5 \mathrm{SD}))$ were removed. The outcome variables were dichotomised and coded as ' 1 ' and ' 0 ', representing those who have the outcome variables (stunting, wasting, concurrent WaSt, LBW, overweight/obesity and DBM) and who did not, respectively. For continuous variables, age, for instance, the distributional assumption of normality was examined by the Shapiro-Wilk test to choose the appropriate measure of central tendency. Frequency, percentage, mean, and SD were used to describe demographic and other variables.

A $\mathrm{X}^{2}$ test was employed and the binary logistic regression analysis was applied for variables that satisfy the $\mathrm{X}^{2}$ test assumption. All variables, irrespective of their statistical significance in the bivariable analysis, were entered into the multivariable logistic regression model to control the possible effects of confounder $/ \mathrm{s} .{ }^{45}$ Prior to identifying the significant factors, the presence of multicollinearity was examined using the Pearson correlation coefficient. The Hosmer and Lemeshow test was used to diagnose the model adequacy. Finally, in the multivariable regression analysis, variables having a $\mathrm{p}$ value of at most $5 \%$ were reported as having independent associations with the outcome variables, adjusted OR (AOR) with its corresponding $95 \%$ CI used as a measure of the strength and the direction of the association.

\section{RESULTS}

\section{Sociodemographic characteristics}

A total of 419 study participants were included to estimate stunting and LBW, making the response of $99.3 \%$. After 
Table 1 Sociodemographic characteristics of mothers who had delivered at the University of Gondar Comprehensive Specialized Referral Hospital, northwest Ethiopia, 2020

\begin{tabular}{|c|c|c|c|}
\hline Characteristic & & Number & Per cent \\
\hline \multirow[t]{3}{*}{ Age of mother } & $10-19$ & 30 & 7.6 \\
\hline & 20-35 & 309 & 78.4 \\
\hline & $>35$ & 55 & 14 \\
\hline \multirow[t]{2}{*}{ Religion } & Orthodox & 339 & 86.0 \\
\hline & Muslim & 55 & 14.0 \\
\hline \multirow{4}{*}{$\begin{array}{l}\text { Educational } \\
\text { status of the } \\
\text { mother }\end{array}$} & No schooling & 108 & 27.4 \\
\hline & Primary school & 75 & 19.0 \\
\hline & Secondary school & 101 & 25.6 \\
\hline & Higher education & 110 & 27.9 \\
\hline \multirow{4}{*}{$\begin{array}{l}\text { Educational } \\
\text { status of the } \\
\text { father }\end{array}$} & No schooling & 92 & 23.4 \\
\hline & Primary school & 87 & 22.1 \\
\hline & Secondary school & 98 & 24.9 \\
\hline & Higher education & 117 & 29.7 \\
\hline \multirow[t]{3}{*}{$\begin{array}{l}\text { Occupation of } \\
\text { mother }\end{array}$} & $\begin{array}{l}\text { Government } \\
\text { employee }\end{array}$ & 95 & 24.1 \\
\hline & Housewife & 255 & 64.7 \\
\hline & Merchant & 44 & 11.2 \\
\hline \multirow[t]{2}{*}{ Birth status } & Single & 385 & 97.3 \\
\hline & Multiple & 9 & 2.7 \\
\hline \multirow[t]{5}{*}{ Wealth index } & Richest & 75 & 19.0 \\
\hline & Richer & 80 & 20.3 \\
\hline & Middle & 78 & 19.8 \\
\hline & Poorer & 80 & 20.3 \\
\hline & Poorest & 81 & 20.6 \\
\hline
\end{tabular}

excluding extremely preterm newborns and those whose length was less than $45 \mathrm{~cm}, 394$ newborns were considered to estimate wasting and overweight/obesity. ${ }^{35}$ The sociodemographic and other relevant findings of stunting are available in the previously published article. ${ }^{46}$ The mean age of the mothers was $27.51(\mathrm{SD}=5.46)$ years and $20.3 \%$ of mothers were from the poorer wealth group. Almost all $(97.6 \%)$ participants were Amhara by ethnicity and $72.8 \%$ were urban dwellers.

Slightly lower than a quarter $(24.1 \%)$ of the mothers were government employees and more than one-fourth $(27.4 \%)$ of them had no schooling at all. The majority $(97.3 \%)$ of the newborns were single birth and a bit higher than half $(54.6 \%)$ of the newborns were male (table 1).

\section{Maternal and anthropometric measurements}

The majority of the mothers $(94.4 \%)$ had at least one ANC visit and $87.6 \%$ of them had taken iron supplementation during pregnancy. More than two-thirds of the mothers $(70.1 \%)$ were multigravidas, $34.5 \%$ were primiparous, $9.9 \%$ had a short interbirth interval and $8.9 \%$ had pregnancy-induced hypertension.
Table 2 Maternal characteristics and anthropometric measurement of newborn-mother pairs recruited at the University of Gondar Comprehensive Specialized Referral Hospital, northwest Ethiopia, 2020

\begin{tabular}{llrl}
\hline Characteristics & Number & Per cent \\
\hline Iron intake & Yes & 345 & 87.6 \\
during & No & 49 & 12.4 \\
pregnancy & & 118 & 29.9 \\
Gravidity & Primigravida & 276 & 70.1 \\
& Multigravida & 136 & 34.5 \\
Parity & Primiparous & 258 & 65.5 \\
& Multiparous & 354 & 89.8 \\
Height of the & Tall & 40 & 10.2 \\
mother & Short & 256 & 65 \\
MUAC & Normal & 138 & 35 \\
\hline Birth status & Chronic malnutrition & 385 & 97.7 \\
& Single & 9 & 2.3 \\
Illness during & GDM & 7 & 1.8 \\
pregnancy & PIH & 35 & 8.9 \\
& Anaemia & 21 & 5.3 \\
\hline
\end{tabular}

GDM, gestational diabetes mellitus; MUAC, mid-upper arm circumference; PIH, pregnancy-induced hypertension.

The mean birth weight of the newborns was 3080.20 (SD $457.97 \mathrm{~g}$ ) while the median newborn's length was $48.0 \mathrm{~cm}$ at the second percentile. More than threefourths $(80.7 \%)$ of newborns had an appropriate birth weight for age. The mean maternal MUAC was 24.55 (SD $2.58 \mathrm{~cm}$ ) and the median gestational age was 39 weeks at the second percentile. The mean height of the mother was 154.73 (SD $7.33 \mathrm{~cm}$ ). Well over one-third (38.2\%) of mothers were malnourished while $10.7 \%$ of them had short stature (table 2).

\section{Environmental characteristics}

A bit more than two-thirds $(66.2 \%)$ of the newborns were conceived in Belg (spring) season and $15.5 \%$ of the mothers had been exposed to indoor fire smoke during the current pregnancy.

\section{Prevalence of malnutrition}

A bit higher than a quarter $(26.6 \%)$ of newborns is stunted, while the tiny proportion $(2.5 \%)$ of newborns is both wasted and stunted (figure 1).

\section{Factors associated with malnutrition among newborns}

As presented in the table below, variables denoted by 'N/A' are those that did not fulfil the $\mathrm{X}^{2}$ assumption. Since all variables for concurrent WaSt as well as the DBM fail the $\mathrm{X}^{2}$ assumption, only descriptive findings are reported.

The odds of LBW were more than twofold $(\mathrm{AOR}=2.8$; 95\% CI: 1.19 to 6.65 ) higher for newborns whose fathers 


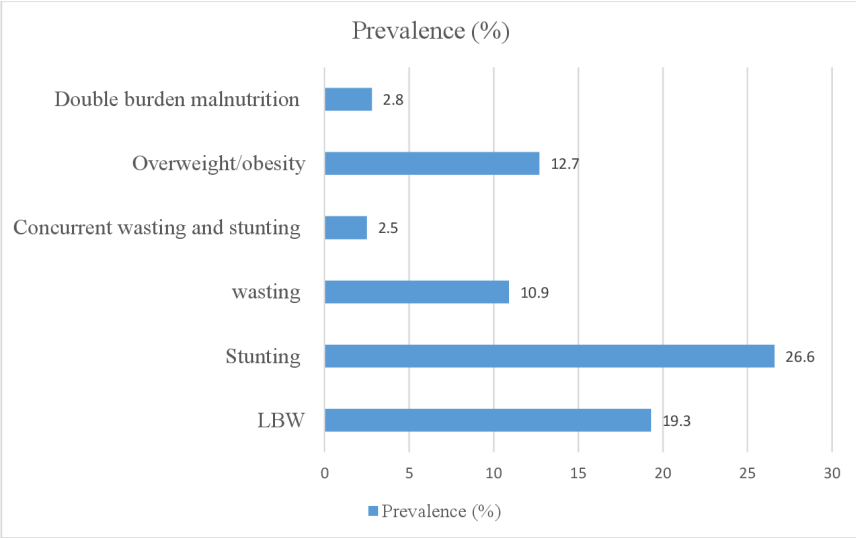

Figure 1 A figure depicting the burden of malnutrition among newborns delivered at the University of Gondar Comprehensive Specialized Referral Hospital, northwest Ethiopia, 2020. LBW, low birth weight.

had attained a primary level of education than newborns whose fathers attained a higher level of education. Likewise, the odds of having LBW were higher among stunted newborns (AOR $=3.1 ; 95 \%$ CI: 1.6 to 6.0 ) as compared with non-stunted newborns. The risk of overweight/ obesity was reduced by $65 \%$ (AOR $=0.35 ; 95 \%$ CI: 0.12 to 0.99) among newborns whose mothers were from rural as compared with urban dwellers. None of the investigated variables were statistically associated with wasting at birth (table 3).

\section{DISCUSSION}

The deleterious effect of undernutrition on children is well-established evidence and it is more severe among children having the concurrent form of the nutritional disorder. Malnutrition at birth has a permanent lifethreatening impact on the physical health and cognitive performance of children. ${ }^{47}$ A newborn's malnutrition is the main testimony for improper prenatal nutrition and a powerful predictor of infant survival. ${ }^{48} 49$ The risk of mortality among newborns with multiple anthropometric deficits is higher than those having a single nutritional problem. ${ }^{50}$ Studies aiming to estimate the prevalence of multiple forms of malnutrition and factors have a paramount impact on battling malnutrition at birth. ${ }^{51}$ Thus, this study aimed at estimating both undernutrition and overnutrition among newborns.

The study highlights that just over 1 in every $10(12 \%)$ and $26.6 \%$ of newborns were overweight/obese and stunted, respectively. Besides, about 28 newborns from 1000 have DBM. This suggests that DBM is becoming an emerging challenge in impoverished areas of the world, including Ethiopia. ${ }^{52}$ In stunted newborns, there are impaired fat oxidation and low-resting energy expenditure, thus the result of these adaptations could facilitate fat storage and being overweight that drove children to DBM. ${ }^{22} 53$ The implication is that the intrauterine period is a window of opportunity to tackle the concomitant occurrence of stunting and overweight/obesity.
The study has also evidenced that $26.6 \%$ and $10 \%$ of newborns experienced stunting and wasting, respectively. Similarly, 2.5\% of newborns have concurrent (WaSt) forms of malnutrition. The burden was highly prevalent among newborns born to chronically malnourished mothers and newborns who were small for gestational age, which was also the case in previous findings. ${ }^{22}{ }^{48}$ The growth and development of the fetus is the interaction between the intrinsic growth pattern itself and environmental factors, including maternal and paternal genetics, maternal size and the capacity of the placenta to supply essential nutrients that enable the fetus to mature. ${ }^{25}$ Although malnutrition among newborns is the interwoven effect of the aforementioned important factors, the nutritional status of mothers, both low pre-pregnancy Body Mass Index (BMI) and insufficient gestational weight gain, take the biggest share of the problem. ${ }^{54}$ Parental genetics and having a healthy and capable placenta to supply nutrients are not the guaranty to attain the nutritional requirement of the fetus unless the mother has all the essential nutrients to be provided. ${ }^{27}$ Likewise, wasting and stunting are often present in a similar population and they share many causal factors. ${ }^{89}$ Hence, the promotion of maternal nutrition should be considered to reduce the problem of 'multiple anthropometric deficits' of newborns that risks them to serious morbidity as well as mortality. ${ }^{9}$ Investing in methods that make the intrauterine growth as healthy as possible through maintaining gestational weight gain as per the pre-pregnancy BMI could be one strategy that professionals in the field should consider. This might be the way forward to end childhood malnutrition.

The proportion of newborns in the current study having LBW is relatively higher than the pooled prevalence reported in 30 studies in Ethiopia. ${ }^{55}$ Various factors might be considered to explain the observed difference. The former finding was an aggregate of various studies from different settings with better economic status while the current study was conducted in the poorest region of the country. ${ }^{55}$ The method used across these studies is also distinct; the current study ascertained LBW by adjusting for the length of the newborns for the corresponding gestational age, unlike the previous studies that used simply the weight of the baby without considering the effect of the maturity level (gestational age) on birth weight. In light of the observed arguments, it is recommended for future scholars to consider the gestational age while determining LBW and stunting to bring credible evidence and avoid misleading data. ${ }^{37}$

In agreement with the previous study, this study underscores that a low level of paternal education is significantly associated with increased odds of LBW. ${ }^{56}$ Better social support is one of the factors that positively contributes to pregnancy care and a healthy pregnancy period. In this respect, fathers are the most intimate and responsible people to provide the required social support for their pregnant wives to have a healthy pregnancy and healthier newborn. ${ }^{57}$ 
Table 3 Summary findings from multivariable logistic regression where outcomes are wasting, low birth weight and overweight/obesity of newborns delivered at the University of Gondar Comprehensive Specialized Referral Hospital, northwest Ethiopia

\begin{tabular}{|c|c|c|c|c|c|c|}
\hline \multirow[b]{2}{*}{ Variables } & \multicolumn{2}{|c|}{ Low birth weight } & \multicolumn{2}{|c|}{ Wasting only } & \multicolumn{2}{|c|}{ Overweight/obesity } \\
\hline & AOR & $95 \% \mathrm{Cl}$ & AOR & $95 \% \mathrm{Cl}$ & AOR & $95 \% \mathrm{Cl}$ \\
\hline \multicolumn{7}{|l|}{ Age } \\
\hline$<19$ & 0.46 & 0.15 to 1.39 & N/A & N/A & $\mathrm{N} / \mathrm{A}$ & $\mathrm{N} / \mathrm{A}$ \\
\hline $20-35$ & 1 & 1 & N/A & N/A & N/A & N/A \\
\hline$>35$ & 0.87 & 0.39 to 1.90 & N/A & $\mathrm{N} / \mathrm{A}$ & $\mathrm{N} / \mathrm{A}$ & $\mathrm{N} / \mathrm{A}$ \\
\hline \multicolumn{7}{|l|}{ Residence } \\
\hline Rural & 1.37 & 0.62 to 3.03 & 1.12 & 0.49 to 2.54 & $0.35^{*}$ & 0.12 to 0.99 \\
\hline Urban & 1 & 1 & 1 & 1 & 1 & 1 \\
\hline \multicolumn{7}{|l|}{ Religion } \\
\hline Muslim & 1.12 & 0.49 to 2.52 & 2.07 & 0.66 to 6.48 & 1.24 & 0.39 to 4.01 \\
\hline Orthodox & & & 1 & 1 & 1 & 1 \\
\hline \multicolumn{7}{|c|}{ Educational status of the father } \\
\hline No schooling & 1.48 & 0.42 to 5.14 & 1.02 & 0.23 to 0.46 & 0.48 & 0.12 to 2.19 \\
\hline Primary & $2.82^{*}$ & 1.19 to 6.65 & 0.72 & 0.19 to 2.62 & 0.59 & 0.17 to 2.00 \\
\hline Secondary & 1.95 & 0.71 to 5.36 & 1.64 & 0.61 to 4.38 & 0.68 & 0.25 to 1.85 \\
\hline Higher education & 1 & 1 & 1 & 1 & 1 & 1 \\
\hline \multicolumn{7}{|c|}{ Educational status of the mother } \\
\hline No schooling & 1.36 & 0.35 to 5.32 & 2.54 & 0.45 to 14.41 & 1.41 & 0.25 to 8.09 \\
\hline Primary & 0.52 & 0.15 to 1.78 & 1.65 & 0.34 to 8.18 & 1.63 & 0.35 to 7.59 \\
\hline Secondary & 1.22 & 0.45 to 3.30 & 2.56 & 0.72 to 9.12 & 0.85 & 0.24 to 2.98 \\
\hline Higher education & 1 & 1 & 1 & 1 & 1 & 1 \\
\hline \multicolumn{7}{|l|}{ Occupation of the mother } \\
\hline Government employee & 1 & 1 & 1 & 1 & 1 & 1 \\
\hline Merchant & 1.17 & 0.43 to 3.19 & 0.52 & 0.21 to 1.98 & 0.33 & 0.09 to 1.18 \\
\hline Housewife & 0.71 & 0.21 to 2.44 & 0.79 & 0.09 to 7.05 & 0.92 & 0.24 to 3.45 \\
\hline \multicolumn{7}{|l|}{ Wealth index } \\
\hline Richest & 1 & 1 & 1 & 1 & 1 & 1 \\
\hline Richer & 0.9 & 0.40 to 2.06 & 0.69 & 0.25 to 1.98 & 2.02 & 0.69 to 5.89 \\
\hline Middle & 1.07 & 0.48 to 2.44 & 0.62 & 0.21 to 1.83 & 1.20 & 0.41 to 3.58 \\
\hline Poorer & 1.44 & 0.63 to 3.27 & 0.75 & 0.26 to 2.19 & 1.35 & 0.45 to 4.03 \\
\hline Poorest & 0.45 & 0.17 to 1.18 & 1.12 & 0.40 to 3.04 & 1.53 & 0.50 to 4.69 \\
\hline \multicolumn{7}{|l|}{ Sex of the newborn } \\
\hline Male & 0.97 & 0.57 to 1.66 & 0.90 & 0.46 to 1.75 & 1.01 & 0.56 to 1.99 \\
\hline Female & 1 & 1 & 1 & 1 & 1 & 1 \\
\hline \multicolumn{7}{|c|}{ Iron intake during pregnancy } \\
\hline Yes & 1 & 1 & 1 & 1 & 1 & 1 \\
\hline No & 0.86 & 0.32 to 2.34 & 0.60 & 0.19 to 1.89 & 0.75 & 0.26 to 2.16 \\
\hline \multicolumn{7}{|l|}{ Parity } \\
\hline Multipara & 0.58 & 0.32 to 1.6 & 0.32 & 0.04 to 2.63 & 1.37 & 0.27 to 6.90 \\
\hline Primiparous & 1 & 1 & 1 & 1 & 1 & 1 \\
\hline \multicolumn{7}{|l|}{ ANC } \\
\hline Yes & 1 & 1 & N/A & N/A & $N / A$ & N/A \\
\hline No & 1.45 & 0.36 to 5.79 & N/A & $\mathrm{N} / \mathrm{A}$ & N/A & $\mathrm{N} / \mathrm{A}$ \\
\hline
\end{tabular}


Table 3 Continued

\begin{tabular}{|c|c|c|c|c|c|c|}
\hline \multirow[b]{2}{*}{ Variables } & \multicolumn{2}{|c|}{ Low birth weight } & \multicolumn{2}{|c|}{ Wasting only } & \multicolumn{2}{|c|}{ Overweight/obesity } \\
\hline & AOR & $95 \% \mathrm{Cl}$ & AOR & $95 \% \mathrm{Cl}$ & AOR & $95 \% \mathrm{CI}$ \\
\hline \multicolumn{7}{|c|}{ Intention of pregnancy } \\
\hline Not intentional & 0.99 & 0.37 to 2.65 & N/A & N/A & N/A & $\mathrm{N} / \mathrm{A}$ \\
\hline Intentional & 1 & 1 & $N / A$ & N/A & $\mathrm{N} / \mathrm{A}$ & $\mathrm{N} / \mathrm{A}$ \\
\hline \multicolumn{7}{|c|}{ Height of the mother } \\
\hline Short & 0.61 & 0.26 to 1.47 & N/A & N/A & $\mathrm{N} / \mathrm{A}$ & $\mathrm{N} / \mathrm{A}$ \\
\hline Tall & 1 & 1 & $\mathrm{~N} / \mathrm{A}$ & N/A & $\mathrm{N} / \mathrm{A}$ & $\mathrm{N} / \mathrm{A}$ \\
\hline \multicolumn{7}{|l|}{ MUAC } \\
\hline Malnutrition & 0.72 & 0.37 to 1.39 & 1.5 & 0.60 to 2.63 & 0.97 & 0.48 to 1.95 \\
\hline Normal & 1 & 1 & 1 & 1 & 1 & 1 \\
\hline \multicolumn{7}{|l|}{ Length for age } \\
\hline Short for age & 3.17 & 1.6 to $6.0 \dagger$ & $\mathrm{N} / \mathrm{A}$ & N/A & $\mathrm{N} / \mathrm{A}$ & N/A \\
\hline Normal & 1 & 1 & $\mathrm{~N} / \mathrm{A}$ & N/A & $\mathrm{N} / \mathrm{A}$ & $\mathrm{N} / \mathrm{A}$ \\
\hline \multicolumn{7}{|c|}{ Season of conception } \\
\hline Kiremt/winter & 0.83 & 0.46 to 1.48 & 0.88 & 0.45 to 1.77 & 0.92 & 0.48 to 1.78 \\
\hline Bega/summer & 1 & 1 & 1 & 1 & 1 & 1 \\
\hline \multicolumn{7}{|c|}{ Exposed to indoor fire smoke } \\
\hline Yes & 0.59 & 0.27 to 1.28 & 1.92 & 0.63 to 5.84 & 1.01 & 0.39 to 2.56 \\
\hline No & 1 & 1 & 1 & 1 & 1 & 1 \\
\hline
\end{tabular}

$N / A=$ variables that do not fulfil the $X^{2}$ assumption.

${ }^{*} \mathrm{P} \leq 0.05=$ strong association.

$\dagger P \leq 0.0001=$ very strong association.

ANC, antenatal care; AOR, adjusted OR; MUAC, mid-upper arm circumference; N/A, not applicable.

Higher level educational attainment of fathers has a significant positive influence on their health service utilisation and healthy practices are better. ${ }^{58}$ In Ethiopia, where there is a low literacy level, the problem is likely affecting thousands of newborns if special emphasis is not in place. Likewise, stunted newborns in the current study tripled the risk of LBW, which was not indicated in previously conducted studies. Different nutritional deficits share similar risk factors; the same is true for LBW and stunting where the prepregnancy weight and gestational weight gain highly determine their occurrence. ${ }^{16}$ Given the higher risk of comorbid illnesses and mortality in newborns with the combined nutritional problems, urgent public health measures should be considered. ${ }^{20}$

In the current study, there were significantly higher odds of overweight/obesity among mothers of newborns residing in an urban area as compared with rural areas, which is in line with the previous report. The rapid increase in overweight/obesity is indicated in urban areas of Ethiopia, asserting it is a major public health concern. ${ }^{59}$ The difference in dietary intake and physical activity could be among the key drivers for the observed urban and rural variation. ${ }^{60}$ Mothers in rural areas of Ethiopia stay engaged in different laborious household and agricultural activities until they give birth that will make them unable to gain optimal gestational weight. ${ }^{60}$ In urban areas, however, mothers usually spend their pregnancy period resting, watching television for a long time, and consuming fortified and manufactured meal products, which collectively put them at risk of attaining high pregnancy weight and ultimately give birth to obese/overweight newborns. ${ }^{61}$ Healthcare providers should, therefore, provide nutrition education for pregnant women along with ANC that mainly focuses on dietary behaviour and dietary preference.

The study has some strengths and admissible limitations. One of the strengths of the current study is providing comprehensive evidence of different anthropometric deficits and their combined occurrence among newborns in a setting where there was no such evidence previously. However, owing to the inaccessibility of data, we did not assess the pre-pregnancy weight and weight gain during pregnancy of mothers, which is presumed to be one of the best indicators of the nutritional status of newborns. Though various strategies were used to control different sources of biases including recall bias, the findings are not completely free from various biases that might have impacted the findings. 


\section{CONCLUSION}

The study remarks that malnutrition among newborns in Ethiopia is a public health problem. Fathers' educational status (low level) and being stunted are associated with a high burden of LBW. Mothers' residency (being urban) elevated the risk of overweight/obesity among newborns. Thus, improving the literacy of fathers and preventing stunting through maintaining intrauterine nutrition are recommended to mitigate $\mathrm{LBW}$ while paying special attention to newborns born from urban resident mothers is necessary to reduce the burden of overweight/obesity. Future scholars in the field are recommended to conduct longitudinal studies to look at the effect of malnutrition at birth on the later nutritional status as well as the growth and development of the victims. Further, it is recommended to ascertain the nutritional status of the newborns (LBW and stunting) using the INTERGROWTH-21st software to account for the gestational age of the newborns.

Acknowledgements We would like to thank the data collectors and colleagues who have contributed to this work. We are also delighted to extend our gratitude to the International Institute of Primary Health Care-Ethiopia (IIPHC-E) for launching a scientific manuscript writing workshop and helping us through preparing this manuscript.

Contributors WWT, EGM, TGA and ATG conceived the idea, designed the study, analysed and interpreted the data, and drafted the manuscript. All authors have agreed on the accountability of this work and approved it for publication. WWT is the guarantor.

Funding The University of Gondar sponsored the study with funding number, UOG/R/01/2020.

Disclaimer The funder did not have a role in the study.

Competing interests None declared.

Patient and public involvement Patients and/or the public were not involved in the design, or conduct, or reporting, or dissemination plans of this research.

\section{Patient consent for publication Parental/guardian consent obtained.}

Ethics approval Ethical clearance was obtained from the ethical review board of the school of nursing on behalf of the institutional review board of the University of Gondar (V/P/RCS/04/651/2020). A permission letter was received from the University of Gondar Comprehensive Specialized Referral Hospital. An information sheet comprised of the purpose of the study, the data collection procedure, and the rights of the mothers was prepared and attached to the protocol. It has been reviewed and approved by the institutional review board. After reading the information sheet to mothers, oral informed consent was obtained since the study did not apply invasive procedures like body fluid samples. Participants' involvement in the study was voluntary and they have been told to withdraw at any time if they wish to. The study participants were informed that all the information given by them will not be used other than the intended research purposes, and confidentiality and privacy will be maintained.

Provenance and peer review Not commissioned; externally peer reviewed.

Data availability statement Data are available upon reasonable request. All data relevant to the study are included in the article or uploaded as supplemental information. All necessary data are supplied and available in the manuscript, however, the corresponding author will provide the dataset upon request.

Open access This is an open access article distributed in accordance with the Creative Commons Attribution Non Commercial (CC BY-NC 4.0) license, which permits others to distribute, remix, adapt, build upon this work non-commercially, and license their derivative works on different terms, provided the original work is properly cited, appropriate credit is given, any changes made indicated, and the use is non-commercial. See: http://creativecommons.org/licenses/by-nc/4.0/.

\section{ORCID iDs}

Almaz Tefera Gonete http://orcid.org/0000-0001-8854-1394

Eskedar Getie Mekonnen http://orcid.org/0000-0002-8558-1718
Wubet Worku Takele http://orcid.org/0000-0003-3121-5808

\section{REFERENCES}

1 ljarotimi OS. Determinants of childhood malnutrition and consequences in developing countries. Curr Nutr Rep 2013;2:129-33.

2 Nandy S, Irving M, Gordon D, et al. Poverty, child undernutrition and morbidity: new evidence from India. Bull World Health Organ 2005;83:210-6

3 Ferreira HdaS, da Silva Ferreira H. Anthropometric assessment of children's nutritional status: a new approach based on an adaptation of Waterlow's classification. BMC Pediatr 2020;20:65.

4 Mwangome M, Ngari M, Bwahere P, et al. Anthropometry at birth and at age of routine vaccination to predict mortality in the first year of life: a birth cohort study in BukinaFaso. PLoS One 2019;14:e0213523.

5 United Nations Children's Fund (UNICEF) WHO, International Bank for Reconstruction and Development/The World Bank. Levels and trends in child malnutrition: key findings of the 2020 edition of the joint child malnutrition estimates. Geneva: World Health Organization, 20202020. https://www.who.int/publications/i/item/jme-2020-edition

6 Abarca-Gómez L, Abdeen ZA, Hamid ZA, et al. Worldwide trends in body-mass index, underweight, overweight, and obesity from 1975 to 2016: a pooled analysis of 2416 population-based measurement studies in 128.9 million children, adolescents, and adults. Lancet 2017;390:2627-42.

7 Novotny R, Li F, Leon Guerrero R, Guerrero RL, et al. Dual burden of malnutrition in US affiliated Pacific jurisdictions in the children's healthy living program. BMC Public Health 2017;17:483.

8 Khara T, Mwangome M, Ngari M, et al. Children concurrently wasted and stunted: A meta-analysis of prevalence data of children 6-59 months from 84 countries. Matern Child Nutr 2018;14:e12516.

9 Myatt M, Khara T, Schoenbuchner S, et al. Children who are both wasted and stunted are also underweight and have a high risk of death: a descriptive epidemiology of multiple anthropometric deficits using data from 51 countries. Arch Public Health 2018;76:28.

10 Bank UWW. Ethiopia's stunting prevalence compared with selected regions of the world, 2018.

11 ICF EPHIEEa. Ethiopia mini demographic and health survey 2019 . key indicators. Rockville, Maryland, USA: EPHI and ICF, 2019.

12 AU C. The cost of hunger in Ethiopia: the social and economic impact of child undernutrition in Ethiopia summary report, 2013.

13 Laillou A, Baye K, Meseret Z, et al. Wasted children and wasted time: a challenge to meeting the nutrition sustainable development goals with a high economic impact to Ethiopia. Nutrients 2020;12:3698.

14 UNICEF. Monitoring the situation of children and women. malnutrition, 2018. Available: http://data.unicef.org/nutrition/ malnutrition.html

15 Olofin I, Flaxman SR, Mascarenhas MN. Associations of suboptimal growth with all-cause and cause-specific mortality in children under five years: a pooled analysis of ten prospective studies. Prevalence 2012;1:10Z.

16 Okubo T, Janmohamed A, Topothai C, et al. Risk factors modifying the double burden of malnutrition of young children in Thailand. Matern Child Nutr 2020;16 Suppl 2:e12910.

17 Mutunga M, Frison S, Rava M, et al. The forgotten agenda of wasting in Southeast Asia: burden, determinants and overlap with stunting: a review of nationally representative cross-sectional demographic and health surveys in six countries. Nutrients 2020;12:559.

18 Berkman DS, Lescano AG, Gilman $\mathrm{RH}$, et al. Effects of stunting, diarrhoeal disease, and parasitic infection during infancy on cognition in late childhood: a follow-up study. Lancet 2002;359:564-71.

19 Ozanne SE, Hales CN. The long-term consequences of intrauterine protein malnutrition for glucose metabolism. Proc Nutr Soc 1999;58:615-9.

20 United Nations Children's Fund (UNICEF) WHO, International Bank for Reconstruction and Development/The World Bank. Malnutrition, 2020.

21 Masood JS. The effect of infant malnutrition on future learning outcomes of children in developing countries. Georgetown University, 2019.

22 Black RE, Victora CG, Walker SP, et al. Maternal and child undernutrition and overweight in low-income and middle-income countries. Lancet 2013;382:427-51.

23 Victora CG, de Onis M, Hallal PC, et al. Worldwide timing of growth faltering: revisiting implications for interventions. Pediatrics 2010;125:e473-80.

24 United Nations Children's Fund (UNICEF) WHO, International Bank for Reconstruction and Development/The World Bank. Levels and 
trends in child malnutrition: key findings of the 2020 edition of the joint child malnutrition estimates. Licence: CC BY-NC-SA 3.0 IGO 2020. Geneva: World Health Organization, 2020. https://www.who. int/publications-detail-redirect/jme-2020-edition

25 Sumarmi S. Maternal short stature and neonatal stunting: an intergenerational cycle of malnutrition, 2016.

26 Leroy JL, Olney DK, Ruel MT. PROCOMIDA, a Food-Assisted maternal and child health and nutrition program, contributes to postpartum weight retention in Guatemala: a cluster-randomized controlled intervention trial. J Nutr 2019;149:2219-27.

27 CDC. Pregnancy complications, 2018. Available: https://www. cdc.gov/reproductivehealth/maternalinfanthealth/pregnancycomplications.htm

28 Kuhnt J, Vollmer S. Antenatal care services and its implications for vital and health outcomes of children: evidence from 193 surveys in 69 low-income and middle-income countries. BMJ Open 2017;7:e017122

29 Workicho A, Belachew T, Argaw A, et al. Adolescent pregnancy and linear growth of infants: a birth cohort study in rural Ethiopia. Nutr J 2019;18:22.

30 Solomons NW, Vossenaar M, Chomat A-M, et al. Stunting at birth: recognition of early-life linear growth failure in the Western highlands of Guatemala. Public Health Nutr 2015;18:1737-45.

31 Rashad AS, Sharaf MF. Does maternal employment affect child nutrition status? new evidence from Egypt. Oxford Development Studies 2019;47:48-62.

32 WHO. Global target tracking tool, 2015. Available: http://www.who. int/nutrition/trackingtool

33 NP.Commission. Ethiopia's Progress towards Eradicating Poverty: an Interim Report on 2015/16 Poverty Analysis Study, 2017.

34 Jazeera AA. Amhara region not only the poorest in Ethiopia but also in the world, 2014.

35 WHO. Any mention of the software in published reports should include the following citation of the source: WHO Anthro for personal computers, version 3.2.2, 2011: Software for assessing growth and development of the world's children. Geneva, 2010. https://www. who.int/childgrowth/software/anthro pc manual v322.pdf

36 Hospital UoGCSR. Annual delivery report of Gondar university Comprhensive and Referal hospitals, 2019.

37 Villar J, Cheikh Ismail L, Victora CG, et al. International standards for newborn weight, length, and head circumference by gestational age and sex: the newborn cross-sectional study of the INTERGROWTH21st project. Lancet 2014;384:857-68.

38 Kruger HS. Maternal anthropometry and pregnancy outcomes: a proposal for the monitoring of pregnancy weight gain in outpatient clinics in South Africa. Curationis 2005;28:40-9.

39 World Health Organization,. Immunization, vaccines, and biologicals: implementation research in immunization, 2017.

40 WHO. Report of a who technical consultation on birth spacing Geneva, Switzerland, 2005.

41 Opara El, Zaidi J. The interpretation and clinical application of the word 'parity': a survey. BJOG 2007;114:1295-7.

42 Fite RO, Mohammedamin A, Abebe TW. Unintended pregnancy and associated factors among pregnant women in Arsi Negele Woreda, West Arsi zone, Ethiopia. BMC Res Notes 2018;11:671.

43 CSA I. Central Statistical Agency (CSA) [Ethiopia] and ICF, Ethiopia demographic and health survey. Addis Ababa, Ethiopia and Calverton, Maryland, USA, 2016.
44 Federal HIV/AIDS Prevention and Control Office Federal Ministry of Health July. Guidelines for HIV counselling and testing in Ethiopia, 2007. Available: https://www.who.int/hiv/topics/vct/ETH_HCT_ guidelinesJune26 clean.pdf

45 Sun GW, Shook TL, Kay GL. Inappropriate use of bivariable analysis to screen risk factors for use in multivariable analysis. J Clin Epidemiol 1996;49:907-16.

46 Gonete AT, Kassahun B, Mekonnen EG, et al. Stunting at birth and associated factors among newborns delivered at the University of Gondar comprehensive specialized referral hospital. PLoS One 2021;16:e0245528

47 Khalatbari-Soltani S, Marques-Vidal P. The economic cost of hospital malnutrition in Europe; a narrative review. Clin Nutr ESPEN 2015;10:e89-94.

48 Bosquet Enlow M, Sideridis G, Bollati V, et al. Maternal cortisol output in pregnancy and newborn telomere length: evidence for sexspecific effects. Psychoneuroendocrinology 2019;102:225-35.

49 Boah M, Azupogo F, Amporfro DA, et al. The epidemiology of undernutrition and its determinants in children under five years in Ghana. PLoS One 2019;14:e0219665.

50 Wells JC, Sawaya AL, Wibaek R, et al. The double burden of malnutrition: aetiological pathways and consequences for health Lancet 2020;395:75-88.

51 Santos MP, Turner B, Chaparro MP. The double burden of malnutrition in Peru: an update with a focus on social inequities. Am J Clin Nutr 2021;113:865-73.

52 Gubert MB, Spaniol AM, Segall-Corrêa AM, et al. Understanding the double burden of malnutrition in food insecure households in Brazil. Matern Child Nutr 2017;13:e12347.

53 Jayalakshmi R, Kannan S. The double burden of malnutrition: an assessment of 'stunted child and overweight/obese mother (SCOWT) pairs' in Kerala households. J Public Health Policy 2019;40:342-50.

54 Sumarmi S. Editor maternal short stature and neonatal stunting: an inter-generational cycle of malnutrition. Dalam proceeding of international Conference on health and well being, 2016.

55 Endalamaw A, Engeda EH, Ekubagewargies DT, et al. Low birth weight and its associated factors in Ethiopia: a systematic review and meta-analysis. Ital J Pediatr 2018;44:1-12.

56 Kramer MS. Determinants of low birth weight: methodological assessment and meta-analysis. Bull World Health Organ 1987;65:663.

57 Wado YD, Afework MF, Hindin MJ. Effects of maternal pregnancy intention, depressive symptoms and social support on risk of low birth weight: a prospective study from southwestern Ethiopia. PLoS One 2014;9:e96304

58 Agushybana F. Influence of husband support on complication during pregnancy and childbirth in Indonesia. Journal of Health Research 2016;30:249-55

59 Tebekaw Y, Teller C, Colón-Ramos U. The burden of underweight and overweight among women in Addis Ababa, Ethiopia. BMC Public Health 2014;14:1-11.

60 Abrha S, Shiferaw S, Ahmed KY. Overweight and obesity and its socio-demographic correlates among urban Ethiopian women: evidence from the 2011 EDHS. BMC Public Health 2016;16:1-7.

61 Desalew A, Mandesh A, Semahegn A. Childhood overweight, obesity and associated factors among primary school children in dire dawa, eastern Ethiopia; a cross-sectional study. BMC Obes 2017;4:1-10. 